\title{
NARRATIVAS DE VIDA EM STOP MOTION: UMA ALTERNATIVA PARA O DESENVOLVIMENTO DE MULTILETRAMENTOS
}

\author{
LIFE NARRATIVES IN STOP MOTION: \\ AN ALTERNATIVE FOR THE DEVELOPMENT OF MULTILITERACIES
}

\author{
Isabel Cristina Michelan de Azevedo ${ }^{1}$ \\ Fabiana Santos de Sousa Matos ${ }^{2}$
}

Resumo: Este artigo investiga a produtividade de práticas escolares direcionadas ao ensino de narrativas de memórias/de vida voltadas ao resgate do patrimônio cultural de Salgado/SE, por uma turma de $8^{\circ}$ ano do ensino fundamental. Com base no caráter dialógico da linguagem e na concepção da escrita como processo, em uma pesquisa-ação, foram desenvolvidas atividades direcionadas à produção de histórias que sustentaram a criação de animações em stop motion. Ao final das ações didático-pedagógicas, observamos ser possível desenvolver práticas cooperativas de linguagem com função sócio-histórica e cultural, aprimorar o uso de recursos linguístico na construção dos discursos e favorecer práticas de multiletramentos.

Palavras-chave: produção textual; escrita como processo; processo de ensino-aprendizagem de línguas; animação multissemiótica.

\begin{abstract}
This article investigates the productivity of school practices oriented to the teaching of memory/life narratives aimed at the rescue of the cultural heritage of Salgado/SE, by a group of 8th grade elementary school. Based on the dialogical character of language and the conception of writing as a process, in an action research, activities were developed directed to the production of stories that supported the creation of animations in stop motion. At the end of didactic-pedagogical actions, we observed that it is possible to develop cooperative language practices with a socio-historical and cultural function, to improve the use of linguistic resources in the construction of discourses and to favor multiliteracy practices.
\end{abstract}

Keywords: text production; written as a process; teaching-learning process of languages; multisemiotic animation.

\section{Introdução}

\footnotetext{
${ }^{1}$ Doutora em Letras pela Universidade de São Paulo, atualmente é professora adjunta no Departamento de Letras Vernáculas da Universidade Federal de Sergipe, coordenadora do Mestrado Profissional em Letras, campus São Cristóvão, e líder do Grupo de Pesquisas em Argumentação e Retórica Aplicadas (GPARA) e do grupo de pesquisas Estudos de Linguagem, Argumentação e Discurso (ELAD). E-mail: icmazevedo2@gmail.com

2 Mestre em Letras, formada no Mestrado Profissional em Letras, campus São Cristóvão. E-mail: fabianas.s.matos@hotmail.com.
} 
Este artigo tem por base uma pesquisa realizada no âmbito do Mestrado Profissional em Letras em rede (PROFLETRAS), intitulada "Narrativas de vida em stop motion - uma experiência de ensino de língua portuguesa em práticas de multiletramentos no ensino fundamental", a qual teve como objetivo geral verificar quais práticas pedagógicas são potencialmente produtivas para auxiliar os estudantes do $8^{\circ}$ ano do ensino fundamental na superação das dificuldades de escrita na produção de textos com valor social.

Ao observarmos as produções textuais dos alunos do estudantes do $8^{\circ}$ ano de uma escola pública do povoado Água Fria, no Município de Salgado/SE, no ano de 2018, algumas dificuldades se destacavam: i. os estudantes não se sentiam motivados a escrever e sempre queriam saber qual o total de linhas exigido, se o material solicitado seria avaliado e quem iria ler os textos, deixando claro o receio pela correção da produção; ii. nas escritas que pretendiam fazer o resgate de fatos vividos, os estudantes introduziam um assunto, mas não contavam uma história com ações articuladas; iii. os textos concluídos pareciam distantes da vida concreta.

Por reconhecermos que explorar a língua em uma perspectiva dialógica é uma oportunidade para impulsionar práticas escolares com sentido para todos, o que favorece a formação de sujeitos capazes de produzir escritas vivas, únicas, plena em significados, resolvemos buscar alternativas que pudessem promover na escola práticas processuais, sistemáticas e progressivas de escrita (cf. PASSARELLI, 2012).

Assim, em nossa proposta inicial aos estudantes, sugerimos a construção de narrativas de vida de membros idosos da comunidade local, para que pudessem produzir um texto narrativo completo e lidar com a ordem social em suas histórias, por meio de representações e interpretações de experiências vividas. Com isso, pretendíamos que os estudantes tivessem a chance de produzir uma escrita que tivesse impacto social, uma vez que teriam a oportunidade de reelaborar vivências, recriar o contexto do evento narrado, o que permite construir o mundo da narrativa ao localizar o tempo e o espaço, ao introduzir personagens, suas ações e falas, além de proporcionar práticas de escrita com valor social.

Em nosso modo de ver, esse esforço permitiria aos estudantes compreender que

Tudo o que me diz respeito, a começar pelo meu nome, chega do mundo exterior à minha consciência pela boca dos outros (da minha mãe, etc.), com a sua entonação, em sua tonalidade valorativo-emocional. A princípio eu tomo consciência de mim através dos outros: deles eu recebo as palavras, as formas e a tonalidade para a formação da primeira noção de mim mesmo [...] (BAKHTIN, 2003, p. 373-374).

Ao escrever as histórias com base na vida dos idosos, os estudantes produziram narrativas a partir das quais puderam revisitar suas experiência pessoais e, ao mesmo tempo, 
conhecer os acontecimentos, os valores e as reminiscências do lugar onde vivem, o que promoveu a valorização das experiências dos idosos e ainda contribuiu com a constituição das identidades discentes. Esses atos concretos permitiram partir "do mundo exterior", pela "boca dos outros", para construir discursos marcados pelo pensamento emotivo-volitivo, que “[...] envolve o conteúdo inteiro do sentido do pensamento na ação e o relaciona com o existir-evento singular" (BAKHTIN, 2010 [década de 1920], p. 87).

Por meio das memórias, os estudantes puderam construir narrativas com função social, ampliar seus conhecimentos linguístico-discursivos e sua participação na sociedade, o que colaborou com o desenvolvimento da consciência histórica e cultural da região circundante e de seu grupo social. Isso foi possível porque a língua, além de ser um importante valor cultural, assume-se como registro identitário de uma comunidade, tornando-se um meio essencial para a descoberta e valorização de muitos outros elementos culturais. A consciência que cada um tem de si, a sua existência, é projetada na linguagem, por isso acreditamos que a língua se afirma como um dos elementos identificadores de uma comunidade (cf. BAKHTIN, 2016 [1952-53]).

Além de guiar os estudantes em práticas de escrita com significado e função social, possibilitar a sua imersão em uma atividade humana que mobiliza capacidades variadas, pretendíamos incentivá-los a escrever por meio do uso de múltiplas linguagens disponíveis no contexto social. Isso aconteceu em duas situações distintas: durante a gravação das histórias contadas (momento de valorização da linguagem oral) e, posteriormente, após a escrita das narrativas de vida, na produção de animações em stop motion, isto é, ao criar uma produção artística a partir dos discursos verbais (momento de manuseio de variadas tecnologias, pois houve a necessidade de integrar imagens e sons).

Nessa proposta, procuramos associar o contexto tecnológico vivido por crianças e jovens na atualidade ao desenvolvimento dos multiletramentos, visto que, com as novas mídias, é possível reinventar e renovar as práticas de linguagem. Dessa maneira, a multiplicidade cultural das populações contemporâneas poderia ser alinhada à multiplicidade semiótica de constituição dos textos por meio dos quais elas se informam e se comunicam (ROJO, 2012, p. $13)$.

Embora a opção por multiletrar tenha sido despertada pela observação dos interesses dos estudantes, durante a realização do projeto, também a professora foi impactada e teve que ampliar suas aprendizagens, juntamente com a turma do $8^{\circ}$ ano do ensino fundamental. Por desconhecer a técnica do stop motion, precisou ampliar seus conhecimentos e, sobretudo, passar 
por situações que a aproximou ainda mais dos discentes, pois enfrentou os mesmos desafios técnicos quando tentou criar suas próprias animações. Esse fato promoveu uma olhar em retrospectiva e a constatação de que o projeto didático-pedagógico alcançou os resultados que pretendidos e os estudantes construíram aprendizagens cooperativamente, visto que ao longo da realização das atividades houve negociação conjunta, embora existissem relações hierárquicas desiguais entre os participantes.

Para aprofundar o compartilhamento de saberes e especificar o que foi possível aprender com essa experiência, organizamos este artigo em três partes: na primeira, são elencados os saberes construídos tanto em relação à construção de exemplares do gênero narrativas de memórias/de vida quanto em relação à produção criativa de uma animação em stop motion; na segunda, serão analisados os aspectos observados no conjunto das narrativas verbais produzidas pelos estudantes; na terceira, colocamos em foco uma produção verbal e audiovisual, para aprofundar os resultados alcançados com essa experiência pedagógica.

\section{Aprendizagens em interação: os saberes construídos por estudantes e pelo professor}

A cooperação na prática educacional tem sido realizada em diferentes perspectivas há algum tempo, pois desde o início do século XX diferentes experiências foram conduzidas no sentido de promover a "cooperação educativa” (cf. DEWEY, 1979 [1938]; FREINET, 1974 [1967]; MEIRIEU, 2000 [1984]; FREITAS e FREITAS, 2003, entre outros). Embora sejam variadas as alternativas para a organização das práticas pedagógicas, é consenso favorecer a participação ativa dos estudante no trabalho escolar por meio da valorização do trabalho em grupo e de diferentes modos de interação.

Ciente disso e considerando as diretrizes para a realização de pesquisas no PROFLETRAS, que propõe a consecução de um trabalho de caráter interventivo, pois visa investigar um problema da realidade escolar e/ou da sala de aula, entendemos que era necessário uma mudança no processo de ensino-aprendizagem, de maneira que pudesse haver a ressignificação das práticas escolares. Como apresentamos anteriormente, estávamos preocupadas com os processos pedagógicos e educacionais e com as relações entre os sujeitos sociais, por isso planejamos um trabalho que incentivasse as relações dialógicas e a compreensão ativa dos participantes. Assim, as práticas de leitura e escrita, bem como as oportunidades para a ampliação do letramento digital dos estudantes, incluíram todos, discentes 
e a professora/pesquisadora, em processos reflexivos que instigaram a participação em social e a análise crítica do mundo da vida e da cultura (BAKHTIN, 2010 [década de 1920]).

Em síntese, estudantes e professores participaram de uma construção compartilhada do saber. O professor, no lugar daquele que possui mais experiência nos usos da linguagem, interveio mediando as relações entre o estudante e o conhecimento, pois realizou explicações, apresentou exemplos, organizou orientações etc., ingredientes importantes do processo de ensino que visa ao desenvolvimento dos estudantes. Por sua vez, os estudantes, puderam expressar suas avaliações sobre a realidade vivida dentro e fora da escola, como um ato de resposta frente às questões em análise. Nesse processo, as palavras ganharam vida, uma vez que estavam vinculadas aos contextos histórico, social e cultural e foram expressas em função das relações instauradas com o outro.

Por meio da integração de ações e da inter-relação entre os diferentes discursos, os estudantes e o professor puderam construir saberes bastante variados, pois as práticas escolares puderam motivar os sujeitos à produção de sentidos. Ou seja: a participação ativa na produção histórica de conhecimentos e as relações sociais vividas revelaram possibilidades para a conexão dos saberes com os muitos objetos da vida cotidiana, possibilitando compreender que "as nossas práticas mobilizam vários tipos de ‘saberes', na verdade vários tipos de aprendizados, várias formas do aprender, para atingir um objetivo, em um determinado contexto" (CHARLOT, 2007, p. 50). Em particular, o estudo das práticas discursivas constituídas na sala de aula configurou-se como um caminho viável para a formação e transformação dos sujeitos escolares, principalmente em decorrência da cooperação estabelecida entre todos.

A fim de compartilhar com outros docentes da área de língua portuguesa como o processo de aprendizagem cooperativa ocorreu e de registrar o alcance desse tipo de ação pedagógica, decidimos apresentar, de maneira comparativa, os saberes que foram construídos por meio de uma sequência de atividades, organizada em sete oficinas de trabalho, voltadas tanto à produção de narrativas escritas quanto ao processo de produção de animações em stop motion.

\subsection{Saberes relativos à produção de narrativas de memória/de vida}

Quando escolhemos trabalhar com o gênero narrativas de memórias/de vida, logo nos confrontamos com a ausência de material teórico específico que pudesse orientar as práticas pedagógicas. Encontramos muitas informações acerca da construção de narrativas em geral, o 
que exigiu delimitação de fontes, pois precisávamos de algo que estivesse alinhado à proposta de escrita sugerida aos estudantes. Diante disso, resolvemos, com base no estudo de um conjunto de materiais, elaborar uma descrição que nos auxiliasse no planejamento das ações didáticas. Esse processo aconteceu em parceria com os estudantes, uma vez que as respostas deles diante das atividades realizadas em classe conduziram a professora na busca de novas referências ou no aprimoramento dos exercícios previstos. Assim, ao mesmo tempo, estudantes e a professora construíram saberes importantes em relação ao gênero escolhido.

Quadro 1 - Caracterização do gênero narrativa de memória/de vida

\begin{tabular}{|c|c|}
\hline Saberes construídos pelos estudantes & Saberes construídos pelo professor \\
\hline $\begin{array}{l}\text { - O ato de narrar ocorre no ambiente familiar } \\
\text { quando escutamos histórias contadas por pais } \\
\text { ou avós, mas na escola torna-se mais elaborado } \\
\text { porque é preciso recapitular e reorganizar as } \\
\text { experiências passadas antes de iniciar a escrita } \\
\text { e ainda atender às exigências formais da língua, } \\
\text { para poder circular em sociedade. }\end{array}$ & $\begin{array}{l}\text { - O ato de narrar é uma atividade de linguagem, } \\
\text { constituído por relações dialógicas, que se } \\
\text { concretiza em gêneros discursivos: enunciados } \\
\text { concretos, únicos, que circulam em certos } \\
\text { campos da atividade humana, possui conteúdo } \\
\text { temático e têm construção composicional e } \\
\text { estilo próprios. }\end{array}$ \\
\hline $\begin{array}{l}\text { - Narrar acontecimentos ou eventos requer } \\
\text { organizar uma sucessão de ações, em um tempo } \\
\text { e espaço definidos pelo autor/narrador. }\end{array}$ & $\begin{array}{l}\text { - Narrar acontecimentos vividos diferencia-se } \\
\text { de relatar uma sequência de experiências ou } \\
\text { elaborar um relatório de atividades. }\end{array}$ \\
\hline $\begin{array}{l}\text { - Quando narramos, os fatos ocorridos se } \\
\text { misturam com outras emoções e/ou ideias, por } \\
\text { isso recriamos os contextos de vida na escrita. }\end{array}$ & $\begin{array}{l}\text { - Quando narramos, interagimos com diferentes } \\
\text { vozes por meio do uso da língua/linguagem, em } \\
\text { uma atitude responsiva ativa. }\end{array}$ \\
\hline $\begin{array}{l}\text { - A narrativa de vida contém resumo/prefácio, } \\
\text { orientação, ação complicadora, resultado ou } \\
\text { resolução, coda, avaliação e precisa apresentar } \\
\text { credibilidade. }\end{array}$ & $\begin{array}{l}\text { - As partes que compõem as narrativas de vida } \\
\text { são construções dialógicas de um "eu" situado } \\
\text { social e historicamente, que colaboram com a } \\
\text { organização dos discursos. }\end{array}$ \\
\hline $\begin{array}{l}\text { - O narrador pode escrever em primeira ou } \\
\text { terceira pessoa, a depender do ponto de vista } \\
\text { assumido na escrita. A escolha por uma forma } \\
\text { ou outra depende da intenção comunicativa. }\end{array}$ & $\begin{array}{l}\text { - O discurso alheio é transferido para o contexto } \\
\text { autoral por meio de diferentes recursos que } \\
\text { retomam outras enunciações em discursos } \\
\text { citados e/ou relatados. }\end{array}$ \\
\hline $\begin{array}{l}\text { - Os pretéritos registram fatos passados e } \\
\text { permitem articular as ações narradas, e as } \\
\text { personagens podem ser referenciadas de } \\
\text { diferentes maneiras. }\end{array}$ & $\begin{array}{l}\text { - Os variados recursos linguístico-discursivos } \\
\text { colaboram com o acabamento estético da } \\
\text { narrativa e registram o tom volitivo-emocional } \\
\text { da expressividade. }\end{array}$ \\
\hline $\begin{array}{l}\text { - As recordações incluem conhecimentos, } \\
\text { sentimentos, crenças etc. de diferentes pessoas. }\end{array}$ & $\begin{array}{l}\text { - As memórias pessoais integram-se a outras } \\
\text { familiares, de grupo e sociais. }\end{array}$ \\
\hline $\begin{array}{l}\text { - A memória dos idosos permite conhecer } \\
\text { brincadeiras, jogos, cantos e danças que } \\
\text { foram/são importantes em uma comunidade. }\end{array}$ & $\begin{array}{l}\text { - A memória dos idosos evoca experiências } \\
\text { profundas que permitem ressignificar } \\
\text { paisagens, tradições, valores, culturas etc. }\end{array}$ \\
\hline
\end{tabular}

Fonte: Síntese da consulta a Labov e Waletzky (apud BASTOS, 1992), Bastos (2005), Bakhtin (2003 [1979], 2016 [1952-53], Volóchinov (2017 [1929] e Bosi (1994). 
No quadro 1, observamos que os estudos realizados colaboraram com a formação de todos em níveis diferentes de complexidade, embora seja importante reforçar que as necessidades apontadas pelos estudantes serviram de "bússola" para as novas pesquisas por parte da professora, indicando haver uma interdependência positiva entre os envolvidos na tarefa de produzir narrativas de memória/de vida com valor social. Além disso, a preocupação com a aprendizagem dos estudantes impulsionou a docente a aprofundar seus conhecimentos acerca das possibilidades de ampliação das capacidades discentes, a acompanhar continuamente o desenvolvimento de cada um deles e a assumir que a heterogeneidade constitutiva da linguagem é produtiva nas relações pedagógicas. Construiu-se, assim, uma compreensão plena, real, ativamente responsiva (BAKHTIN, 2016 [1952-53], p. 272) por ambas as partes.

Ao longo das atividades de leitura e escrita, percebemos que o trabalho cooperativo requer a previsão de espaço e tempo para as interações entre os estudantes, de tempo para reflexão, a realização de constantes feedbacks e de um tipo de avaliação processual que permita rever os encaminhamentos de acordo com dados observados no cotidiano escolar.

\footnotetext{
Trata-se de um movimento da consciência responsavelmente consciente, que transforma uma possibilidade na realidade de um ato realizado, de um ato de pensamento, de sentimento, de desejo, etc. Com o tom emotivo-volitivo indicamos exatamente o momento de meu ser ativo na experiência vivida, o vivenciar da experiência como minha: eu penso-ajo com o pensamento. [...] Este relacionar a experiência a mim como ativo tem um caráter valorativo-sensorial e volitivorealizador e é, ao mesmo tempo, responsavelmente racional (BAKHTIN, 2010 [década de 1920], p. 91).
}

Como consequência dos esforços empreendidos por todos e do modo com os pensamentos, os sentimentos, as percepções se integraram às ações, observamos uma melhoria das relações interpessoais e também da autoestima; mais aceitação de perspectivas alheias; a renovação das atitudes frente às tarefas, aos conteúdos estudados, à escola, aos colegas, aos familiares etc., enfim, a assunção de um papel ativo frente ao outro por meio de um processo de comunicação discursiva (BAKHTIN, 2016 [1952-53], p. 273). Tais atitudes tornaram-se ainda mais presentes no momento de realização das oficinas voltadas à criação de animações.

\subsection{Saberes relativos à produção de animações em stop motion}

A técnica de animação stop motion é considerada uma técnica cinematográfica simples, caracterizada pelo trabalho de articular fotos de objetos, reunidas fotograma por fotograma, a outros recursos semióticos. Entre um fotograma e outro, o animador muda a posição do objeto 
da forma mais minuciosa possível, para que, ao ser passadas rapidamente, seja proporcionada a ilusão de que o objeto está se movimentando. Para isso, deve-se projetar a animação a 24 fotogramas por segundo, em uma produção profissional; contudo, em ambiente escolar, a animação pode obter resultados satisfatórios quando projetada de 10 a 15 fotogramas por segundo. As animações em stop motion podem ser produzidas utilizando fotogramas criados a partir de recortes, massinhas, arames, bonecos, entre outros materiais, assim, devido ao baixo custo, torna-se uma oportunidade de desenvolvimento de multiletramentos viável em muitas escolas públicas.

Ao iniciar o projeto de adaptação das narrativas de memória/de vida verbais em criações artísticas, os estudantes e a professora identificaram-se pela falta de informações específicas relacionados à utilização da técnica stop motion. Dessa maneira, a sala de aula tornou-se verdadeiramente um espaço cooperativo e colaborativo, uma vez que todos poderiam contribuir com a construção dos conhecimentos. Para que os alunos recebessem treinamento apropriado com relação à técnica, a própria professora assistiu a vídeos disponíveis no YouTube e produziu uma animação ("A casa"3) para vivenciar todas as etapas pelas quais os estudantes iriam passar.

$\mathrm{Na}$ criação artística, por meio da técnica stop motion, todos vivenciaram o excedente da visão estética, pois os conhecimentos em relação ao mundo e a apropriação que houve por parte dos sujeitos escolares durante a escrita da narrativa de memória/de vida e a elaboração da animação se articularam sob a singularidade dos diferentes lugares ocupados no mundo. Esse excedente de visão possibilitou a contemplação do outro, sem perder a originalidade deste, e uma visão axiológica do mundo, produzida de dentro dele, em um movimento de acabamento/conclusibilidade. Vemos, então, que "a atividade estética começa propriamente quando retornamos a nós mesmos e ao nosso lugar fora da pessoa [...], quando enformamos e damos acabamento ao material [...] pela via em que preenchemos o material [...] através dos elementos transgredientes a todo o mundo material [...] (BAKHTIN, 2003 [1979], p. 25). Isso permite compreender que, em uma perspectiva dialógica,

[os] elementos da vida são reorganizados de modo a compor uma nova unidade, da qual o próprio "autor-criador" aparece como sendo ao mesmo tempo um elemento constituinte e organizador. O autor aparece como a apropriação de uma voz social que ordena o todo estético e essa ordenação é sempre um "ato valorativo", mas ela só se realiza porque a ele é conferida ao mesmo tempo uma posição privilegiada em relação ao [...] seu mundo: uma posição exterior [...] (GLOSSÁRIO, 2018).

\footnotetext{
${ }^{3}$ Disponível em: https://www.youtube.com/watch?v=KtdxHffIo0c\&feature=youtu.be. Acesso em 13 jun. 2018.
} 
Consideramos importante ressaltar que a produção do curta-metragem, na forma de uma animação em stop motion, configurou-se como uma adaptação de uma narrativa escrita, ou seja, tratou-se de uma segunda criação estética. Ao adaptar uma narrativa escrita para a linguagem visual, os discentes realizaram as alterações necessárias de modo a tornar a produção do stop motion possível com os recursos disponíveis na escola, tendo como resultado algo inédito e de sua autoria, construído de modo colaborativo e participativo. Esses atos concretos exigiram o conhecimento de alguns elementos fotográficos próprios da linguagem visual, que foram aprendidos ao longo do processo, pelos estudantes e pela professora que queriam expressar seu dizer por meio de variados recursos.

Bakhtin (2016 [1952-53]) salienta que é possível acessar a realidade por meio dos gêneros discursivos. Como o curta-metragem é um enunciado da esfera artística e permite estabelecer relações dialógicas entre os sujeitos sociais, pode ser considerado um gênero discursivo. Notamos que, por meio dele, é possível manter vínculos com a realidade social e, por sua conotação discursiva muito marcante, pode ser utilizado como instrumento de crítica social a partir de registros audiovisuais, como é o caso das animações produzidas a partir deste projeto pelos estudantes, cuja forma de comunicação envolveu a sincronização de diversas linguagens que devem estar em sintonia, harmonia e coerência para que possa ser transmitido o sentido desejado por sujeitos sociais.

Como tentamos descrever, a produção dos curtas permitiu práticas de multiletramentos pelos discentes, haja vista que eles transformaram um registro escrito para a linguagem artística que envolveu diversas outras linguagens, implicadas na técnica stop motion, possibilitando aos estudantes conhecimento e entretenimento, além de permitir significar e ressignificar a concepção de prática pedagógica. Isso porque, ao utilizar a técnica, as aulas passaram da transmissão oral e escrita, sistematizada por textos didáticos e científicos, para a interação propriamente dita, o que permitiu a utilização de diversos recursos semióticos: som, fotografias, animações, vídeos. Assim, percebemos que esse tipo de trabalho contribuiu para a construção de uma educação conectada com as necessidades atuais e para a produção de saberes plurais, coletivos e interativos (ROJO, 2012).

Ao longo das atividades, as habilidades sociais foram desenvolvidas, e a professora pode assumir o papel de mediador que fornecia aos grupos orientações direcionadas à consecução do projeto e à avaliação do funcionamento de cada grupo. Como as aulas aconteceram de maneira 
colaborativa, a professora se apresentou como uma parceira das novas descobertas e também pode desenvolver as habilidades sociais necessárias ao bom desempenho dos trabalhos em grupo.

Ao final, além de promover motivação intrínseca para o trabalho escolar, melhoria das aprendizagens na escola, redução de problemas disciplinares, foram desenvolvidas capacidades diversificadas e, sobretudo, o pensamento crítico.

Em vista disso, para favorecer o alcance das ações pedagógicas empreendidas, a seguir, passamos à apresentação dos resultados alcançados pelos estudantes no que se refere à produção de narrativas de memória/de vida.

\section{Análise das narrativas dos estudantes}

Objetivamos nesta seção apresentar o resultado da análise das narrativas dos estudantes, organizada pela professora/pesquisadora com o intuito de apontar se os estudantes conseguiram ou não produzir textos relativos ao gênero discursivo narrativas de memórias/de vida. Para tanto, avaliamos, em conjunto, as cinco narrativas produzidas que foram escolhidas pelos próprios estudantes para a produção dos curtas-metragens, seguindo critérios de análise estabelecidos coletivamente ${ }^{4}$ entre os estudantes e a docente. Para fazer referência às narrativas dos estudantes, foram criadas nomenclaturas de identificação que seguiram a seguinte ordem: gênero feminino / masculino + iniciais dos dois primeiros nomes do estudante que produziu a narrativa + numeração, seguindo a ordem alfabética dos nomes, a saber: MCH01; MJP02; FMB03; FRS04 e FSV05.

Em relação aos critérios de adequação das escritas ao gênero proposto inicialmente, verificamos que os cinco exemplares conseguiram construir satisfatoriamente uma narrativa de memória/de vida, segundo a estrutura descrita por Labov e Waletzky (1967), pois observamos referências ao local no qual as histórias se situavam, houve demarcação do tempo no contexto narrativo, a trama estava dividida em partes, contendo ação complicadora, desenlace do conflito e desfecho da história. A avaliação dos acontecimentos por parte dos narradores ocorreu de maneira diversa e o elemento "coda" foi produzido de modo variado: em duas narrativas, apresentou-se de forma avaliativa; em uma, como forma de moral; nas outras duas, não apareceu, conforme a síntese apresentada a seguir.

\footnotetext{
${ }^{4}$ Critérios para a seleção da narrativa: a) história que contenha o máximo de elementos de uma narrativa; b) aquela que possua a ação complicadora bem desenvolvida como melhor clímax e desfecho; c) a que tenha reminiscências de hábitos, costumes, valores e relações da comunidade local; d) a que utilize as formas discursivas (diretas e indiretas) de modo adequado; e) a que faça demarcação do tempo passado; f) a que seja considerada mais atraente.
} 
Quadro 2 - Identificação dos elementos constitutivos das narrativas de memória/de vida

\begin{tabular}{|c|c|c|c|c|c|}
\hline $\begin{array}{c}\text { Funções características da composição } \\
\text { narrativa }\end{array}$ & 宅 & 气ે & $\sum_{i=1}^{m}$ & $\begin{array}{l}\vec{\Xi} \\
\frac{\alpha}{\Sigma} \\
\frac{\alpha}{\Sigma}\end{array}$ & $\sum_{0}^{\infty}$ \\
\hline $\begin{array}{l}\text { Orientação - situa o leitor em relação à pessoa, ao } \\
\text { lugar, ao tempo, à situação comportamental (função } \\
\text { referencial) }\end{array}$ & $X$ & $X$ & $X$ & $X$ & $X$ \\
\hline $\begin{array}{l}\text { Ação complicadora (ou complicação) - é constituída } \\
\text { por ações marcadas temporalmente, que conduzem o } \\
\text { leitor ao clímax do acontecimento. }\end{array}$ & $\begin{array}{l}\text { em } \\
\text { parte* }\end{array}$ & $X$ & $X$ & $X$ & $X$ \\
\hline $\begin{array}{l}\text { Avaliação - é a parte que revela a atitude do narrador } \\
\text { em relação à narrativa, por meio da qual é possível } \\
\text { apresentar juízos de valor, crenças etc. }\end{array}$ & $X$ & $X$ & $X$ & $X$ & $X$ \\
\hline $\begin{array}{l}\text { Resolução (ou resultado) - apresenta o desenlace dos } \\
\text { acontecimentos, por isso o texto pode terminar nesta parte. }\end{array}$ & $X$ & $X$ & $X$ & $X$ & $X$ \\
\hline $\begin{array}{l}\text { Coda - é um mecanismo funcional que faz com que a } \\
\text { perspectiva verbal volta ao momento presente. }\end{array}$ & $X$ & & $X$ & & $X$ \\
\hline
\end{tabular}

Fonte: Dados da pesquisa, organizados com base em Labov e Waletzky (apud BASTOS, 1992).

Como pode ser observado no quadro 2, os estudantes demonstram apropriação em relação aos elementos essenciais de organização da narrativa, conforme proposição de Labov e Waletzky, posto que todos souberam dividir as partes do texto adequadamente em uma narrativa de memória/de vida e utilizaram os elementos próprios da construção composicional do gênero. Destacamos que apenas um dos estudantes, MJP02, empregou o discurso direto em sua produção textual e fez isso de modo adequado ao discurso.

Nos textos dos estudantes, todos os elementos estão bem ordenados, o que torna a construção textual clara e coerente, apresentam organização textual, tempo narrativo cronológico e linear. Em síntese, são produções narrativas bem desenvolvidas e apresentam linguagem apropriada ao gênero do discurso.

Além disso, os estudantes demonstraram compreender que as marcas linguísticas cumprem importantes papéis na construção das narrativas de memória/de vida. Isso pode ser observado na adequação no uso dos pretéritos; no uso de circunstanciadores temporais (como: "certo dia", "na manhã seguinte", "naquela noite", "em um dia", "ao final do dia" etc.) e de circunstanciadores espaciais (como: "em seu sítio", "ao lado de sua residência", "em casa" etc.); 
variaram as formas de referenciar as personagens (protagonistas e antagonistas), pois utilizaram nomes próprios, pronomes pessoais diretos, oblíquos, de maneira a colaborar com a progressão do enredo; souberam utilizar de maneira adequada o discurso direto e indireto; indicando que compreenderam como os elementos linguísticos colaboram com a construção dos discursos.

Em relação à mobilização de aspectos culturais e sociais decorrentes do contexto social na escrita, observamos que os estudantes fizeram descrições de festas típicas do local onde vivem (como: festas de reisado), tematizaram a vida simples de pessoas no campo tanto no ambiente familiar quando na roça, destacaram que os valores sociais criam conflitos pessoais e comunitários, enfim, assumiram a posição de sujeitos responsivos ao compreender ativamente as histórias ouvidas dos idosos, reorganizaram as informações associadas à vida em sociedade, produziram um discurso único e concreto, com base em discursos alheios. Observamos que os estudantes manifestaram de forma ativa o seu ponto de vista acerca da palavra do outro, por meio do discurso citado que é "[...] o discurso dentro do discurso, o enunciado dentro do enunciado, mas ao mesmo tempo é o discurso sobre o discurso, o enunciado sobre o enunciado" (VOLÓCHINOV, 2006 [1929]), p. 249).

Logo, confirmamos que as histórias produzidas pelos estudantes foram construídas a partir do discurso ouvido, mas não são meros recontos e reproduções, são novas criações, percebidas em um plano plástico-pictural de uma certa visão estética, elaboradas pelo ouvinte com base em sua imaginação criadora, que se projeta a partir do mundo da percepção real (BAKHTIN, 2003 [1979], p. 26-27).

Por fim, destacamos que os estudantes conseguiram produzir narrativas situadas social e historicamente a partir de um processo interacional e dialógico com o discurso do idoso e, consequentemente, com os contextos sociais, confirmando que essas produções decorrem dos diálogos constituídos com outros discursos com os quais tiveram contato dentro e fora da sala de aula.

Para ilustrar como esse trabalho impactou a produção discursiva dos estudantes, passamos, a seguir, a comparar o texto inicial e final de $\mathrm{MCH} 01$ e incluiremos alguns elementos da produção audiovisual do grupo 1 .

\section{Análise comparativa de narrativas e apresentação da animação em stop motion}

Na produção inicial de MCH01, abaixo, recolhida na sondagem realizada pela professora antes do início do projeto, notamos que são listadas ações cotidianas, frequentemente vividas por 
pessoas da região rural e urbana de um pequeno lugarejo no interior de Sergipe, mas não se identifica uma ação complicadora, há apenas o registro de lembranças passadas junto aos amigos de infância.

Eu lembro que eu soutava pipa com os meus amigos, eu ia para a escola do meu povoado e tarde nois ia brinca de amarelinha.

Eu chamava meus amigos para brinca de cavalo no fundo da casa como tava muito ventando eu ia solta pipa eu não sabia muito, não depois de um tempo meus amigos ea solta pipa no campo eu ai para nois solta pipa como estivesse correndo. Para brincar do cavalo nois pegava um pau e amarava um cordão para dizer que era um cabesto nois pegava uma ripa e batia no pau. Eu estava na casa da minha tia brincando como meu primo de cavalo tinha um pé de pimenta e eu peguei uma pimenta e passei nos olhos e meu primo na boca nois chorou muito. Depois que passou nois foi brinca de novo. Só resta saudades (MCH01).

Essa construção composicional é típica de relatos, nos quais são encontrados uma descrição de acontecimentos. Esse tipo de escrita, segundo Perroni (1992), pode ser considerada uma protonarrativa, visto que as ações apoiadas em experiências pessoais são elencadas ("Eu lembro que eu soltava pipa com meus amigos", "ia para a escola", "chamava meus amigos para brinca de cavalo" etc.), encontram-se comentários ("eu não sabia muito", "Só resta saudades"), mas não há criações imaginárias em torno dos elementos recortados da vida. Além disso, não são identificados a complicação, com sucessivo clímax, nem um desfecho que situasse o personagem em um enredo temporalmente organizado, e o texto é escrito em apenas dois parágrafos.

Após a realização das sete oficinas - a saber: $1^{\mathrm{a}}$ Animação em stop motion; $2^{\mathrm{a}}$ Estudo do gênero narrativas de memórias/de vida; $3^{\mathrm{a}}$ Características composicionais do gênero narrativas de memória/de vida; $4^{\mathrm{a}}$ Características linguísticas e estilísticas do gênero narrativa de memória/de vida; $5^{\mathrm{a}}$ Planejamento de entrevista a ser realizada com idosos da região; $6^{\mathrm{a}}$ Produção do gênero narrativa de memória/de vida; $7^{\text {a }}$ Transformação da narrativa verbal em curta-metragem por meio da técnica do stop motion -, todas as produções estavam adequadas ao gênero, como pode ser observado no exemplar a seguir:

Ana gostava muito das festas de reisado que ia na adolescência por que eram mais seguras do que as de hoje em dia, ela gostava de ir para essa com seus irmãos, José, João e Maria.

Certo dia, em uma dessas festas, Ana começou a dançar muito com seus colegas achando tudo interessante, como a simples maneira das pessoas se vestirem. Ela também estava admirada com a beleza do reisado e do "Bumba-meu-boi". Só que de repente, o Bumba-meu-boi foi para cima dela e ela se assustou muito porque pensou que ele ia pegá-la.

Ela saiu correndo da festa e todo mundo começou a procurá-la, mas não a encontrou mais, porque ela tinha ido embora assustada. 
Depois desse dia, Ana nunca mais foi para a festa do reisado, porque ficou com muito medo, mas ela tem boas lembranças de momentos felizes que viveu nessa festa! (MCH01)

A história inicia de forma adequada ao contexto narrativo, apresenta referências ao local ("festas de reisado"), ao tempo ("na adolescência da protagonista") e às pessoas envolvidas (os “irmãos: José, João e Maria”), situando o leitor em relação aos aspectos constitutivos da história, o que marca a parte de orientação do texto, segundo as características organizadas por Labov.

No segundo parágrafo, a ação complicadora se desenvolve e o enredo torna-se mais elaborado, pois faz referência a uma festa típica de certa regiões brasileiras (“o reisado”). O leitor é situado em relação ao tempo ("certo dia") e quanto ao espaço narrativo ("em uma dessas festas") e tem início a sequenciação de ações relativas à história de Ana: a personagem começou a dançar na festa com o "bumba-meu-boi", mas acontece algo inesperado que muda o estado da situação culminando no clímax (o boi vai "para cima dela e ela se assusta muito por que pensou que ele ia pegá-la").

O narrador poderia ser mais detalhista na narração do acontecimento e na explicação das ações do boi antes dele ir para cima de Ana. Isso ficou evidente para os próprios estudantes no momento das construções do curta-metragem, pois perceberam que faltavam detalhes para o preenchimento de ações do boi durante a narração do curta-metragem, ocasionando a retomada ao que o estudante ouviu da história contada pela idosa.

A seguir, é apresentado o resultado da narrativa, mostrando como ocorreu o desenlace do conflito: "Ela saiu correndo da festa e todo mundo começou a procurá-la, mas não a encontrou mais, porque ela tinha ido embora assustada". E, por fim, é apresentado uma coda avaliativa na qual a sentença retorna o tempo do falante e faz uma avaliação das emoções de Ana a partir de suas lembranças existentes sobre o evento vivido:

Depois desse dia, Ana nunca mais foi para a festa do reisado, porque ficou com muito medo, mas ela tem boas lembranças de momentos felizes que viveu nessa festa! (MCH01).

Tais evidências mostram que, além do estudante compreender a realidade social do indivíduo ao produzir uma narrativa de memória/vida de modo contextualizado, ele também conseguiu se apropriar das particularidades do discurso narrativo sabendo organizá-lo de modo coerente e coeso adequado à estrutura composicional, mobilizada e explorada em sala de aula, a partir de Labov: 
Orientação: quem, onde, o que, quando?

Ação complicadora: então aconteceu o quê?

Avaliação: e daí?

Resultado ou resolução: no fim aconteceu o quê?

Coda: elemento da narrativa menos encontrado; não é uma resposta às perguntas anteriores; ela elimina questões; sinaliza que as perguntas da ação complicadora e da avaliação não são mais relevantes. (LABOV, 1972 apud BASTOS, 1992).

Também notamos que MCH01 utilizou os verbos flexionados no pretérito ao registrar um acontecimento que ocorreu no passado, revelando adequação a uma época ou a um passado vivido e incluiu outras formas de referência a momentos anteriores, como "certo dia".

Observamos ainda que a personagem principal é referenciada de variadas maneiras, ora pelo pronome "ela" ora pelo seu próprio nome e até pela forma oblíqua "la", e que é incluído um antagonista (o "Bumba-meu-boi") que persegue Ana e altera seus sentimentos em relação à tradicional festa. Tais marcas de terceira pessoa do discurso mostram que o estudante soube satisfatoriamente reportar a narrativa de vida do idoso, além de compreender linguisticamente como se manifesta um narrador observador que narra acontecimentos dos quais não participa como personagem. Nessa narrativa não há presença do discurso direto, a narradora não tenta transcrever as falas específicas da personagem, mas se reporta ao discurso da idosa compreendendo-o responsivamente e registra-o de modo coeso e coerente.

Na parte da orientação da narrativa, MCH01 descreve as festas de reisado em que Ana ia na adolescência como sendo mais seguras do que as de hoje, tecendo uma comparação entre as duas épocas da vida da personagem protagonista da narrativa, revelando a avaliação da sociedade de uma época passada como tendo menos violência que a atual. Além disso, MCH01 destaca a maneira simples das pessoas se vestirem, o que mostra um outro traço cultural na interpretação social, e ainda ressalta a beleza do "bumba-meu-boi”, que é um símbolo cultural do folclore brasileiro. Nesse sentido, o estudante produz uma narrativa situada social e historicamente que produz significado para ele e para os leitores.

Por fim, na produção de MCH01, os sinais de pontuação são utilizados corretamente, como o ponto final para finalizar os parágrafos, as vírgulas para elencar os nomes dos irmão de Ana (José, João e Maria) e demarcar expressões temporais e locativas ("certo dia", "depois desse dia", "em uma dessas festas"), o que favoreceu a leitura em voz alta, quando foram produzidos os áudios para integrar o curta-metragem "As lembranças de Ana da festa de reisado" $"$.

\footnotetext{
5 O vídeo se encontra no canal do YouTube: https://www.youtube.com/watch?v=C2PwFYWJd-
} w\&feature=youtu.be . 
No processo de transformação da narrativa verbal em animação audiovisual foram seguidas seis etapas - a saber: $1^{\mathrm{a}}$ cada grupo escolheu uma das narrativas produzidas com base em critérios elaborados coletivamente; $2^{\mathrm{a}}$ elaboração da storyline $e^{6} ; 3^{\mathrm{a}}$ Elaboração de sinopse $^{7}$; $4^{\mathrm{a}}$ Construção das personagens, cenários e reunião de objetos; $5^{\mathrm{a}}$ Captação de imagens; $6^{\mathrm{a}}$ Edição, efeitos e finalização para publicação -, envolvendo todos no trabalho com variados recursos semióticos.

Ao longo desse processo, conteúdos bastante técnicos foram estudados pela professora/pesquisadora e, consecutivamente, foram discutidos com os estudantes. Assim, foram selecionados os aplicativos que seriam utilizados para produção, edição e compilação das animações, a saber: Estúdio Stop Motion e KineMaster, nas versões para celular. O processo técnico profissional de adaptação de narrativas para animações em stop motion foi simplificado, de modo a tornar possível a execução dos trabalhos em sala de aula, por exemplo: não foi utilizado computadores (somente aparelho celular) nem material profissional de iluminação, os bonecos não eram próprios de stop motion (por serem recursos muito caros), deu-se destaque para a exploração da linguagem fotográfica/cinematográfica, a exemplo da exploração dos planos de cena de modo a desenvolver a capacidade de interpretação e adaptação do estudante:

Figura 1 - Planos de cena
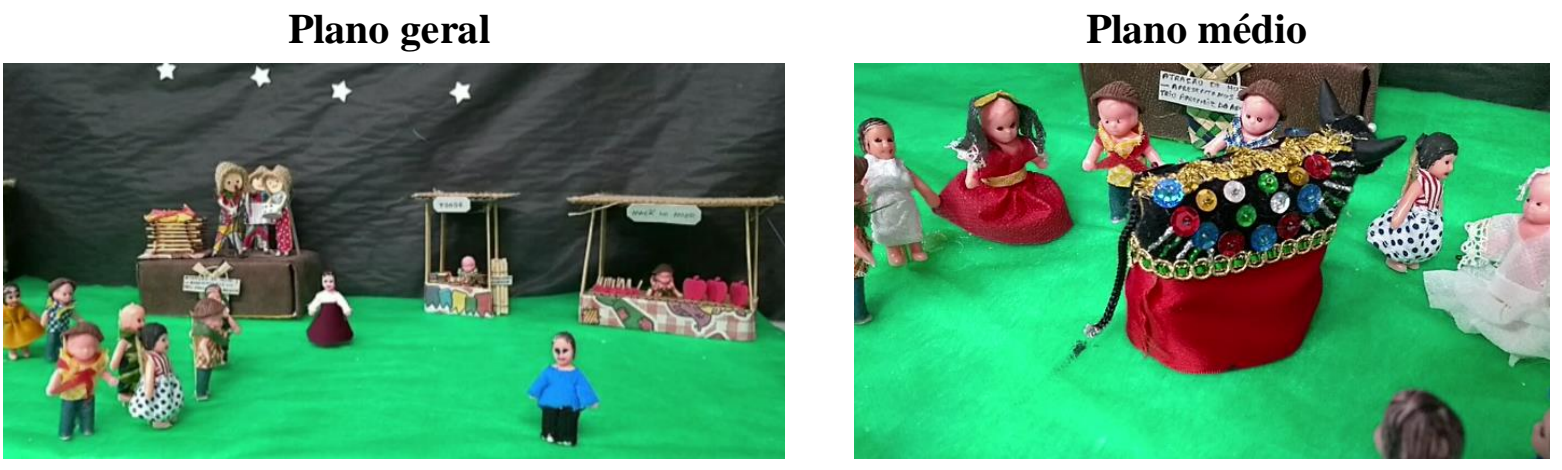

No plano geral é exposto uma grande parte do cenário para mostrar o ambiente e sua localização, desse modo, no momento da fotografia, a câmera deve estar longe do objeto. Isso pode causar, por exemplo, a impressão de solidão ou liberdade. Na animação acima, buscou-se

\footnotetext{
${ }^{6}$ Storyline é o "termo que designa o enredo, a trama de uma estória. Como uma 'story-line’ deve ter no máximo 5 linhas, deduz-se que 'story-line' é a síntese da estória [...]”, que deve abranger tudo que a estória normalmente conteria, ou seja: 1. Apresentação do conflito; 2. Desenvolvimento do conflito; 3. Solução do Conflito” (COMPARATO, 1983, p. 53).

${ }^{7}$ Sinopse é o desenvolvimento da storyline de modo a contemplar os detalhes principais da história que se quer contar: quando, onde, quem (OLIVEIRA, 2010).
} 
deixar claro para o espectador como era o local onde a festa do reisado se realizou, mostrando pessoas reunidas, barracas e um grupo musical. O plano médio ou intermediário é aquele no qual a câmera não deve ficar muito distante. Costuma-se chamar de plano de posicionamento e movimento. Nesse curta, o plano médio serviu para destacar a ação do Boi Bumbá direcionada à Ana.

Concluímos que a atividade em stop motion permitiu inserir os estudantes em uma prática que exige a mobilização de diversas linguagens (sonora, fotográfica e visual) para a produção de sentidos a partir da narrativa reconstruída. Além disso, por exigir um trabalho em grupo, essa prática possibilitou o diálogo, e a capacidade de interpretar e de se expressar por meio da dublagem, no momento de fazer a fala do narrador.

Assim, essas atividades de produção em contextos variados foram pensadas como forma de favorecer a multiplicidade semiótica de constituição dos textos, favorecendo a renovação e reinvenção das práticas docentes, para que fosse possível não somente letrar, mas, principalmente, multiletrar (ROJO, 2012), ao levar os estudantes a compreenderem, interpretarem e produzirem em diversas linguagens, semioses e mídias envolvidas na criação de significação desse texto multimodal.

Convém destacar que o curta-metragem facilitou o processo de reconstrução da narrativa, pois, para a sua produção, o estudante precisou situar personagens em um tempo e espaço, vivendo uma situação particular. Assim, afirmamos que a produção do curta-metragem possibilitou que os estudantes aprimorassem as suas capacidades de narrar de maneira dialógica e responsiva diante da história de vida ouvida e produzida, estabelecendo, neste novo contexto de produção, uma interação dinâmica entre essas dimensões discursivas.

\section{Considerações finais}

O projeto desenvolvido nesta pesquisa foi um grande desafio, uma tarefa difícil, mas também gratificante para a docente/pesquisadora. A aplicação de uma proposta didática inovadora confirmou ser possível ampliar os conhecimentos de linguagem dos estudantes, promover a participação social e que, ao mesmo tempo, possibilitar a inclusão de ferramentas tecnológicas em sala de aula, desde que sejam concretizados esforços amplos e variados.

A partir da problemática de escrita evidenciada em sala de aula no início do projeto, refletimos muito acerca de como e por quais meios poderíamos contribuir para a resolução das dificuldades de escrita dos estudantes na produção de textos narrativos. Esse ponto de partida 
estimulou-nos a pensar em uma intervenção que mobilizasse diferentes recursos e possibilitasse alcançar dois objetivos principais: proporcionar práticas de linguagem com função social, histórica e cultural em situações de vida social e práticas de multiletramentos em sala de aula.

A proposta de ensino de produção textual que tinha como atividade final a produção de animações, por meio do stop motion, levou-nos à confirmação de que é possível construir um material replicável que seja acessível ao professor que trabalha na educação básica. Como ensinar não está mais restrito à transmissão de informações e de conteúdos programáticos, mas precisa propiciar situações de aprendizagem, entendemos que as escolhas didáticas podem possibilitar ao professor a diversificação das práticas docentes e aos estudantes acessar conhecimentos sistematizados, desenvolver as suas potencialidades e ampliar a compreensão da realidade em que estão inseridos, para que possam progressivamente ter condições de assumir seu espaço no mundo por meio da palavra/discurso e da ação.

\section{Referências}

AJELLO, Anna Maria. A perspectiva pedagógica no estudo dos processos sociais na escola. In: PONTECORVO, C.; AJELLO, A. M.; ZUCCHERMAGLIO, C. Discutindo se aprende: interação social, conhecimento e escola. Tradução de Cláudia Bressan e Susana Termignoni. Porto Alegre: Artmed, 2005.

BAKHTIN, Mikhail M. Estética da criação verbal. Tradução de Paulo Bezerra. São Paulo: Martins Fontes, 2003 [1979].

Para uma filosofia do ato responsável. Tradução de Valdemir Miotello e Carlos Alberto Faraco. São Carlos: Pedro \& João Editores, 2010.

Os gêneros do discurso. Organização, Tradução, Posfácio e Notas de Paulo Bezerra. São Paulo: Editora 34, 2016 [1952-1953).

BASTOS, Lúcia Kopschitz. Coesão e coerência em narrativas escolares. São Paulo: Martins Fontes, 1992.

BASTOS, Liliana Cabral. Contando histórias em contextos espontâneos e institucionais: uma introdução ao estudo da narrativa. Calidoscópio. Revista de Linguística Aplicada, São Leopoldo, v. 3, n. 2, p. 74-87, 2005.

BOSI, Ecléa. Memória e sociedade: lembranças de velhos. São Paulo: Companhia das Letras, 1994.

CHARLOT, Bernard. Formas do Aprender e "Conexões de Saberes": os significados da noção de conexão quando se trata de saberes. In: SILVA, Veleida A. (Org.). Conexões de saberes: um desafio, uma aventura, uma promessa. São Cristóvão: Editora UFS, 2007, 39-55. 
COMPARATO, Doc. Roteiro. Rio de Janeiro: Nórdica, 1983.

DEWEY, John. Experiência e educação. 3. ed. São Paulo: Companhia Editora Nacional, 1979 [1938].

FREINET, Celestin. O jornal escolar. Tradução de Filomena Quadros Branco. Lisboa: Editorial Estampa, 1974 [1967].

FREITAS, Luísa Varela; FREITAS, Cândido Varela. Aprendizagem cooperativa. Porto: Edições ASA, 2003.

GLOSSÁRIO Bakhtin. In: LINGUAGENS EM INTERAÇÃO: TEORIA DIALÓGICA. Disponível em: <http://linguagenseminteracao.blogspot.com/2012/11/glossario-bakhtin.html>. Acesso em: 31 mai. 2018.

LABOV, William; WALETZKY, Joshua. Narrative Analysis: Oral Versious of Personal Experience. In: HELM, J. (Ed.). Essays on the verbal and visual arts. Washington : University of Washington Press, 1967. p. 12-44.

MEIRIEU, Philippe. Itinéraire des pédagogies de groupe. Apprende en groupe. 7. ed. Saint Martin-en-Haut: Chronique sociale, 2000 [1984].

OLIVEIRA, Flávio Gomes de. Panorama e proposições da animação stop motion. 2010. 213 f. Dissertação (Mestrado em Cultura Visual) - Universidade Federal de Goiás, Faculdade de Artes Visuais, Goiânia, 2010.

PASSARELLI, Lílian Maria Ghiuro. Ensino e correção na produção de textos escolares. São Paulo: Cortez, 2012.

PERRONI, Maria Cecília. Desenvolvimento do discurso narrativo. São Paulo: Martins Fontes, 1992.

ROJO, Roxane. Pedagogia dos multiletramentos: diversidade cultural e de linguagens na escola. In: ROJO, Roxane; MOURA, Eduardo (Org.). Multiletramentos na escola. São Paulo: Parábola Editorial, 2012. p. 11-31.

VOLÓCHINOV, Valentin. Marxismo e filosofia da linguagem: problemas fundamentais do método sociológico na ciência da linguagem. Tradução, notas e glossário de Sheila Grillo e Ekaterina Vólkova Américo. São Paulo: Editora 34, 2017. 